\title{
Current status of Complementary Therapies in Spain in nursing degree
}

\author{
Ana Belén Fernández-Cervilla ${ }^{1}$ \\ Ana Isabel Piris-Dorado ${ }^{2}$ \\ Maria Esperança Cabrer-Vives ${ }^{2}$ \\ Ana Barquero-González ${ }^{3}$
}

\begin{abstract}
Objective: Describe the current situation of complementary therapies in nursing education in schools and nursing schools in Spain. Method: Descriptive study. Study population all faculties andschools ascribed to Spain. Data collection through observation sheet. Analysis units Curricula. Variables (credits, course type, location, type of therapy). Descriptive analysis of relative and absolute data using Excel spreadsheet. Results: Most of the faculties and schoolsofnursingscrutinized the subject of Complementary Therapies has disappeared and those that aparace is an optional subject. Conclusion: Complementary Therapies training in Spain is deficient because it is not collected as a core subject and / or obligatory. The absence of Complementary Therapies in the curriculum, questions such as their value in training, conceptualization which teachers, the impact on quality of care, training of teachers responsible for teaching the subject, as well as the number of credits and the course being in the degree of Grado.
\end{abstract}

Descriptors: Complementary Therapies; Education, Nursing; Students, Nursing.

${ }^{1} \mathrm{PhD}$, Colaborate Professor, Escuela de Enfermería, Universidad de Barcelona, Barcelona, Spain.

2 RN.

${ }^{3}$ PhD, Full Professor, Facultad de Enfermería, Universidad de Huelva, Huelva, Espain.

Corresponding Author:

Ana Belén Fernández Cervilla

Universidad de Barcelona. Escuela de Enfermería

Feixa Llarga $\mathrm{s} / \mathrm{n}$

Pavelló de govern 3 a planta despacho 339

CEP: 08097, Barcelona, España

E-mail: abfernandez@ub.edu 


\section{Introduction}

The growing interest of nursing professionals to know and use what are called Complementary Therapies (CT) is reported in several articles, both in confronting problems related to health, as well as to achieve better levels of well-being, the same reasons why the the population increasingly uses them ${ }^{(1-4)}$.

It is evident that many people resort to all possible means, seeking what allopathic medicine does not offer, such as feeling relaxed, supported, finding moments of well-being, internal power and coping with their situation.

It is also noteworthy that many health professionals feel involved in the challenge of integrating the knowledge they have to give a response, incorporating knowledge of what is called natural medicine into the knowledge acquired in the formation of their professional careers. They have endorsed the idea of Integrative Medicine.

Therefore, in this article we intended to know the level of CT education that was taught to the future nursing professionals in Spain.

There are several terms to describe the same concept, so for the World Health Organization (WHO), "alternative medicine" and "complementary medicine" respond to a given classification in countries where there is no integration between traditional medicine and Western medicine, therefore, they prefer to speak in "terms" of traditional medicine. According to the WHO, this term should refer both to the systems of traditional medicine, as well as various forms of unsystematic indigenous medicine ${ }^{(5)}$. Furthermore, it defines this medicine as "practices, approaches, knowledge and diverse health beliefs incorporating medicines based on plants, animals and / or minerals, spiritual therapies, manual techniques and exercises applied individually or in combination to maintain well-being, as well to treat, diagnose and prevent disease ${ }^{(5)}$. "

There are several classifications of these $\mathrm{CT}$, the most used are published in the report of the White House Commission on Complementary and Alternative Medicine Policy, and the National Center for Complementary and Alternative Medicine (NCCAM) ${ }^{(6)}$ in which five different categories or domains are noted:

- Alternative Medical Systems: Those considered as complete systems of theory and practice, alternative systems to conventional medicine, and that have been practiced mainly in China and India for thousands of years. They include traditional Chinese medicine, Ayurveda, naturopathy and homeopathy;
- Mind body interventions: includes those techniques or interventions that enhance the mind's capacity to affect bodily functions and symptoms. Includes support therapies, cognitive and behavioral therapy, meditation, relaxation and visualization, art therapy, music therapy, etc.;

- Biologically based therapies: those that use natural products, such as dietary herbs, foods and vitamins. (It also includes substances that have not always been scientifically proven, such as shark cartilage to treat cancer ...);

- Methods of manipulating the body: those that emphasize manipulation or movement of one or more body parts. Includes chiropractic, osteopathy, massage, reflexology, among others;

- Energy-based therapies: those based on the manipulation of energy fields and includes two subcategories: Biofield therapies, which affect the energy field that surrounds and penetrates the human body, such as Reiki, therapeutic touch, etc., and bioelectromagnetic therapies, which involve the unconventional use of electromagnetic fields, alternating energy fields, etc.

As for the utilization of $\mathrm{CT}$, the public interest in them is not limited to a particular social class, rural area or regions of low socio-economic development; on the contrary, it reaches all sectors of society ${ }^{(7)}$ with its utilization being very extensive. For example, in African Member States, $90 \%$ of Ethiopia's population uses traditional medicine to help to satisfy the health needs; in Latin America, the practice ascends to $40 \%$ of the population of Colombia, and up to $71 \%$ in Chile. In China, $40 \%$ of the population has used these therapies at some point, because these are widely used in Asia, the traditional medicines of China, Malaysia and India(5).

In other developed countries, widespread use has also been observed: in the United States it has been estimated that the number of visits to alternative medicine establishments ascended to 425 million, a figure that exceeded the number of visits to conventional providers (388 million). Forty-six percent of Australians, $49 \%$ of French and $70 \%$ of Canadians have also used some of these therapies, as well as one in three Germans, with acupuncture and homeopathy being the most used $\mathrm{CT}^{(5)}$.

In Spain, according to the National Institute of Statistics (INS)(8), $5.5 \%$ of the population surveyed in 2003 had consumed alternative medicine products in the previous two weeks, with a wider consumption among women $(7.57 \%)$ than men $(3.46 \%)$; a higher 
use was also observed in people with higher educational preparation, higher professional status, or people aged between 45 and 64 years.

The 2006 survey followed the same pattern and, additionally, an increase in consumption among retirees and housewives was observed.

In the European Health Survey conducted in Spain in 2009, women and people aged between 35 and 54 were observed to be those who made more visits to alternative medicine services in the twelve months prior to the survey, with the autonomous communities of Madrid, Catalonia and Murcia showing the highest use, with a percentage of $7.32 \%, 5.7 \%$ and $4.94 \%$, respectively(8). Likewise, among the group of men who made more visits these included those uncapable of working and those who were employed. In women this pattern was repeated, and those who were unemployed were also added(8)

The reasons that led to increased demand for CT originated in consumer dissatisfaction with conventional medicine and also with the discontent with the manner of care of certain professionals ${ }^{(9)}$. Another author's opinion in this respect was that "given the interest of the users for complementary / alternative medicine (CAM), a system that does not take them into account can not be truly people-centered"(10).

Regarding the legal status of the $\mathrm{CT}$, educated professionals are still finding legal barriers to their implementation, despite the fact that health personnel have been interested in them over the course of the years because of its objective of treating users in a holistic and more humane manner ${ }^{(11)}$.

In Europe, the European Parliament approved, in March 1997, the Paul Lannoye report on the status of $\mathrm{CT}$, in which recommendations were made to member states regarding their recognition, regulation and harmonization $^{(12)}$

In July 1999, the Catalonian Parliament, under the recommendations of the European Parliament, prepared a comprehensive report that served as a base for the present regulation of $\mathrm{CT}^{(12)}$.

In February 2007, the Catalonian government drafted the decree $31 / 2007^{(1,12)}$ which regulated the conditions for the exercise of certain natural therapies, but on July 25 of that same year the Department of Health received notice of interim suspension that the Superior Court of Justice of Catalonia (TSJC) delivered on multiple items following the lawsuit filed by the Ministry of Health, the General Council of the College of Physicians and the College of Physiotherapists of
Catalonia, understanding that the Catalan text was arbitrary for two reasons: it encroached on the powers of the state and allowed the exercise of professions and practices related to the health sector to people without basic qualifications checked by the state.

The Department of Health responded, since it believed it had acted within the scope of competence, demanding a minimum of practical action and the establishments in which they acted, confronting this reality with scrupulous respect of the health professional competencies and, precisely, by putting boundary to the intrusion that could be produced in this legal vacuum. But on June 11, 2009, the TSJC annuled the natural therapies decree of the Government of Catalonia in its entirety ${ }^{(2)}$.

In the wake of this problem, in Catalonia, the CT group of the Official College of Nursing of Barcelona (COIB) presented a project for the approval of the Diploma of Accreditation and Education (DAC) of CT so that they were administratively recognized and regulated in practice $^{(2)}$. It states that, given the limitations of conventional medicine, it is a holistic approach that takes into account the totality of the person and all modes of healing is being sought.

Because of the concern that the CT are offered and applied with greater assurance of quality and safety, implementing them is difficult, although there are several geographic areas where CT education is implemented due to constant use by users ${ }^{(3,5)}$. Thus, in Latin America, the population uses ethnomedicine (folk medicine), whose practice is passed on to health professionals through the creation of a professorship in natural medicine at the University of Las Condes, Santiago, Chile. Currently, a medical specialty of natural medicine exists in Cuba, with a duration of 4 years. In Mexico, a curriculum in complimentary medicine has been developed, and Venezuela recognizes the legalality of $\mathrm{CT}$, so it has created a National Commission on Complementary Therapies, which regulates education in this field and validates degrees and certificates through the Ministry of Health of Venezuela(4). In Peru, some medical schools have hosted conferences on traditional medicine ${ }^{(13)}$

Some North American medical schools, hospitals and other health services offered nonconventional medicine as a therapeutic alternative and teaching, some North American states offer, in their insurance coverage, coverage for nonconventional therapies ${ }^{(12,14-16)}$

In the United States there is no proper university education in natural medicine, although there 
are numerous colleges that provide education in complementary medicine that lasts three to five years. Their programs of study are truly comprehensive and complete. Remember that the naturopathy term comes from the United States, where the trained professionals of these colleges are called "Doctors of Naturopathy"(4).

In Germany, in 1991, a professorship was established in Berlin, directed by Dr. Buring, and in other universities such as Munich, teaching projects in natural medicine have appeared. Since 1993, naturist medicine has been included in German medical curricula education $^{(4)}$.

In France there are about seven universities offering courses in hydrology and many others who teach homeopathy, acupuncture or relaxation therapy. At the University of Bobigny, Paris, studies in naturist medicine have been taught for over twelve years, and the University of Montpellier offers a European diploma in medicinal plants ${ }^{(4)}$.

Education in naturopathy began in Spain in 1989, with the integration of a graduate course ${ }^{(4)}$. There are no official masters which are dedicated to the teaching of the $\mathrm{CT}$, although there are numerous unofficial masters offered by various universities and organizations from many Spanish provinces: Barcelona (IL3-UB, COIB, Colegio Oficial de Médicos de Barcelona (COMB), Madrid (Instituto Superior de Estudios Psicológicos, Universidad de Alcalá de Henares), Zaragoza (Universidad de Zaragoza), Navarra (Universidad Pública de Navarra), Toledo (Universidad Castilla La Mancha), etc. ${ }^{(17) .}$

In Spain, in terms of basic nursing education in CT, pioneers schools were the Escuela de Santa Madrona (1989) and the Escuela Gimbernat (Catalonia) introducing into their core curriculum basic electives in CT; later in the course during 1992-3(18).

The college of nursing at the Universidad de Barcelona (UB), began to offer elective courses such as: relaxation and visualization methods, reflexology and, later in 2006, massage and metamorphic technique. In the graduate level studies, "complementary instruments in graduate nursing care", was offered in the years $1998-2006^{(19)}$. In parallel, the COIB has been offering educational courses in this field since 1995. In 2009, the "Master in Natural Medicine and Natural Nursing" emerged, organized by the Committee of Natural and Complementary Therapies of the Collegial Section of Naturist Physicians of the $\mathrm{COMB}^{(19)}$.

The $\mathrm{CT}$ in nursing practice has been of interest mainly in those areas where there was the need to consider the person within a holistic, comprehensive focus. Florence Nightingale, the driving force of modern nursing, applied a process of observation, with special attention to the environment surrounding the individual. In her writing, Notes on nursing. What it is and what it is not, she conceptualized nursing as responsible for someone's personal health and what the nurse had to do was to put the patient in the best condition for nature to act upon him(20). Thus the integration of holistic practices in nursing education would provide "a new generation of holistic nurse caregivers"(21). This provoked positive changes in the way of care delivery and in the manner of relating with people receiving care ${ }^{(3)}$.

Nursing is a science in continual evolution. This is demonstrated both by curricular changes in the education, as well as competencies in the healthcare field. Over the past forty years this progressed from a Health Technical Assistant (ATS), to University Diploma in Nursing (DUE), until it reached the degree status(22-23).

Recent studies affirmed that the educational development remained primarily linked to the preventive biomedical model, and that conceptions of 'popular' critical education and educational practices are scarce, due to deficient education of the professors ${ }^{(24)}$.

It is of vital importance that all nursing schools are subject ed to universal criteria and standards, to obtain a consensus about the minimum level of education for students, as well as establishing quality standards in nursing education for the country(25).

There is also the need to implement changes in the professional education of nurses, rescuing the humanistic view together with the scientific. It is suggested that in undergraduate courses an interactive methodology is developed, capable of subsidizing the praxis of humane, sensitive and intersubjective care(26).

\section{Rationale and objectives}

Given that no reference exists, it was believed convenient to study how the situation has changed regarding the courses in $\mathrm{CT}$ in nursing education in Spain after the introduction of the degree modality, with the general objective: to describe the current situation of the teaching of CT in faculties, schools and centers of public nursing study and assigned to the Spanish State, and with the following specific objectives: to quantify the proportion of public and attached Spanish Universities that offer CT in their educational teaching plans; to specify in which academic course the subject is studied; to detail the number of credits assigned to the course; to determine the nature of the CT offered. 


\section{Methodology}

This was an observational, descriptive study that was conducted in all schools, colleges and public schools in the Spanish state that offered nursing education in the period of 2011-12. In this case, there were 94 according to the Ministry of Education, Sport and Culture.

The inclusion criteria used were, public nursing colleges and universities attached to the Spanish State, and the exclusion criteria were, private university schools, faculties and nursing schools.

To collect data, we used the following data sources: Websites of Faculties and / or Schools; study plans (SP) and teaching plans (TP) of the subject from different universities.

The SP is the concrete curriculum design in respect to some determined teachings conducted by a university, subject to the common general guidelines and their own corresponding general guidelines, the passing of which gives the right to obtain a university degree of official nature and validity throughout the national territory, once surpassed.

The TP is the central element of the formative action, which allows one to know the number of credits, organization of the distinct elements of the subject around the planning of student activity, becoming the reference guide for orienting the various processes involved in the creation, the selection and edition of Objects of Learning that constituted its content and activities.

The following variables were studied: existence of teaching on CT, university, modality (Degree or Diploma), name of the subject taught, character (mandatory or elective), course in which it was taught, type of therapy provided, number of ECTS credits granted to the subject, understanding by ECTS credit rating unit of academic activity necessary to achieve the objectives of teaching in each subject (RD 1125/2003)*.

As an instrument, an observation spreadsheet was developed to collect all the variables of the study. Procedures for their development have been used as a reference for the SP of nursing in all public universities by the Spanish government in the year 2011-12. Information was collected about the subjects taught in schools and studies offered through the degree by means of access to web pages, communication via email and telephone calls to universities (to access the TP for those who were not on the Web).

Below we have grouped the data into two tables (one with the old diploma and another with the current degree) using Microsoft Excel 2003 software, and different figures related to subsequent analysis were calculated.

Analysis of the data obtained are shown in two tables using Microsoft Excel 2003 software. Subsequently, we performed the calculation of relative and absolute figures in order to make a better analysis of the current situation of the teaching of complementary therapies in nursing, in different universities.

\section{Ethical aspects}

Not applicable, because the source data was public

\section{Results}

The results encountered were classified into two areas: Degree and Diploma. In this study greater importance was given to the data obtained from the teaching plans of degree modality, using the data from the diploma as comparative data of the current situation**.

It was observed that, in the degree form of 94 nursing schools, centers and colleges analyzed, in 20 (21.28\%) subjects taught included CT, with 67 of them $(71.28 \%)$ which offered no related subject. In the remaining seven $(7.45 \%)$ there was no information because these schools were in the process of selection of elective courses to implement. Figure 1.

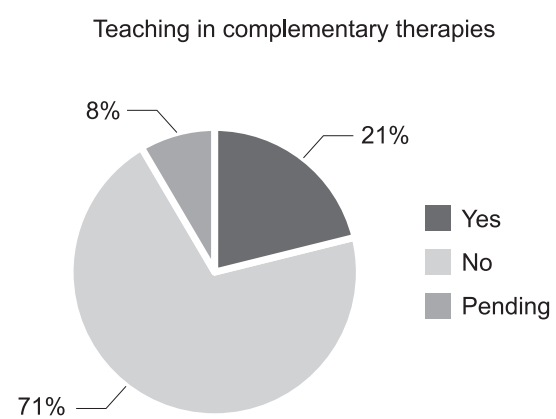

Figure 1 - Distribution of the degree form in schools and colleges of nursing, according to the subjects of $\mathrm{CT}$ in Spain, 2011-2012.

* The European Credits Transfer System is a system focused on the student, that is based on the necessary students' workload for the achivement of the objectives of a program. These obejctives are preferibly specified in terms of the results of learning and the competencies that will be obtained. The value of the credit is between 25 and 30 ECTS.

** Due to the imminent extinction of the Diploma, many colleges no longer consider the TP of electives in TC. 
In 94 nursing schools, centers and universities analyzed that offered the degree modality, in 20 (21.28\%) subjects taught included CT, with 67 of them $(71.28 \%)$ which offered no related subject. In the remaining seven $(7.45 \%)$, there was no information because these schools were in the process of selection of implementing elective courses.
These subjects were present in four of the 17 Autonomous Communities (ACs) and two autonomous cities of Spain (Ceuta and Melilla): Catalonia, Basque Country, Andalusia and the Canary Islands. Twenty of them $(100 \%)$ were of an optional character. (Figure 2 )

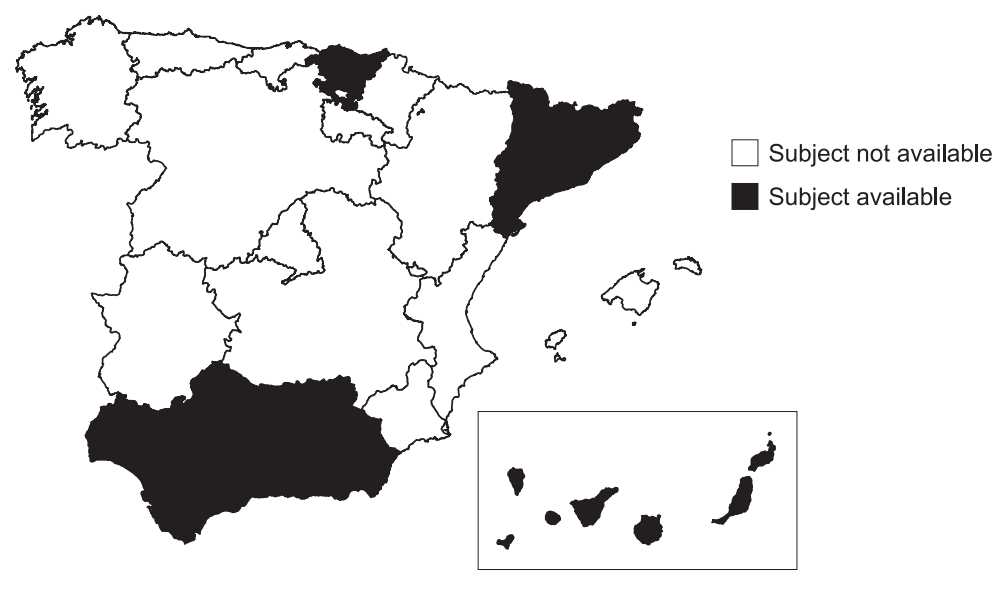

Figure 2 - Communities and Autonomous Cities of Spain in which the delivery of CT subjects were conducted. Spain, 2011-2012

Currently, ten of the 20 subjects (50\%) were implanted; the other ten were approved subjects, which were pending implementation for future academic years.

Regarding academic courses, it was observed that $10 \%(n=2)$ were taught in the first year; $25 \%(n=5)$ in the second; $30 \%(n=6)$ in the third year; while for those that were taught in the last year, the figure rose to $35 \%$ $(n=7)$ (Figure 3).

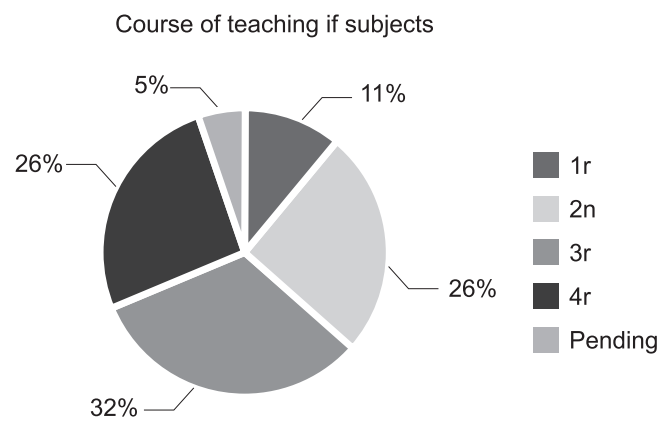

Figure 3 - Distribution of academic courses which taught CT in Spain, 2011-2012

In terms of credits that were quantified in these subjects, there was no information in seven of them $(35 \%)$; of the 13 remaining, $35 \%(n=7)$ were worth 3
ECTS, $5 \%(n=1) 4.5$ ECTS, and 30\% $(n=6)$ were worth 6 ECTS.

The content of the $\mathrm{CT}$ in the established subjects were: foot reflexology, Bach flowers, relaxation and hydrotherapy; others that were less present were acupuncture, massage, therapeutic touch or metamorphic technique, laughter therapy, aromatherapy, phytotherapy, reiki, yoga, music therapies, etc.

\section{Difference between Diploma and Degree}

In a comparative level with the the diploma modality, it was observed that CT in some subjects related to $\mathrm{CT}$ have been supressed in some universities during adaptation to undergraduate studies; among them are the Universidad de Alicante, the schools of nursing of the Ministry of Health and Dependency of the Universidad de Extremadura, the school of nursing of the Universidad de Huelva and the University School of Nursing of Valdecillas of the Universidad de Cantabria.

On the other hand, other universities have added courses to their TP of their SP with the application of the degree modality: Universidad de Sevilla, in the Nursing Center of San Juan de Dios, Francisco Maldonado College Center, Virgen del Rocio Nursing Center and School of Nursing, Physiotherapy and Podiatry; University of Jaén 
in the Faculty of Health Sciences; University of Cádiz in the School of Nursing and Physiotherapy both in Cádiz and the delegation in Jerez de la Frontera and the Universidad de las Palmas de Gran Canaria, both the Las Palmas in the two delegations of Fuerteventura and Lanzarote.

Some universities were also observed that maintained CT subjects, among those, the Universidad de Barcelona of the School of Nursing; the Universidad Autónoma de Barcelona in the School of Nursing of Vall d'Hebrón; Universidad Rovira y Virgili de Tarragona, in the School of Nursing and the Faculty of Health Sciences, now known as the Our Lady of the Snows Nursing Center of the Universidad de Granada.

It is remarkable that, due to the recent introduction of the degree modality and the impending demise of the diploma (in process of being phased out), the information available from the latter has been scarce, so that the comparison between the two modalities is not valuable.

\section{Discussion}

In our literature search we found articles that described in general the situation of the educational framework of CT on a global level(4); there were articles explaining how best to implement $\mathrm{CT}$ in the nursing

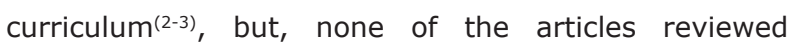
discussed the state of CT education in the nursing curriculum or in the Spanish state, or anywhere else, hence the impossibility of making a comparative analysis with the previous research to the one conducted in this study, therefore we think that this first study may be the gateway to new research to substantiate the importance of $\mathrm{CT}$ and its repercussion in nursing care.

In this academic year the implantation of the degree program is being completed in most Schools and Colleges of Nursing, in the new SP from different centers, the subject of CT that was previously offered has disappeared. Analysis is still pending of the Universities and Schools that have not yet defined the optional subjects of the fourth year of study.

\section{Conclusions}

The results obtained demonstrated the absence of studies about CT education in the Spanish State, this is significant and the value given to such therapies in the nursing core curriculum, the conceptualization that teachers have about them, and if their absence is the result of these previously discussed issues should be investigated
Another consequence arising from this evidence, prevented a comparison of our results with other studies on education in $\mathrm{CT}$, which demonstrated that there is still much work to be done in terms of introducing them in nursing education.

It should be considered that nursing is a personcentered science and one of its main competencies is to have a strong commitment to society, and to provide an answer adjusted to their needs, promoting the free choice of individuals in health decisions and adjusting to bioethical principles; in the majority of cases the CT were absent. Hence the statement that the professional nurse should be knowledgeable about all types of treatments: allopathic, traditional medicine, such as CT. We think that the absence of this education in Spanish universities undermined the treatment and patient counseling; if this deficiency is not corrected there is a risk of having a large number of graduate nurses uneducated about this field and therefore lacking competencies for it. Equally, it would be necessary to reflect and review the degree SP in order to raise awareness about the importance of $\mathrm{CT}$ in nursing education and its implementation as a compulsory subject in response to the population, so we could have nurses competent in the comprehensive care of the population, also responding to the points made in the code of ethics.

It would be necessary to open new lines of research about the education of teachers should have that would teach this subject, and the number of credits and the course being followed for the Degree.

Finally CT research should be strengthened in both academic and care issues (in the public and private environments) to continue to deepen the evidence.

\section{Acknowledgements}

To teachers, principals and employees from different universities throughout Spain who provided the data for this work.

Specially to Professor Julia López for the correction in this work and Rosa Ma Blasco for providing the documentation.

\section{References}

1. Comissió de teràpies naturals del COIB. La sofrologia: Instrument complementari de les cures infermeres. Barcelona; 2011. [acceso en: 14 sep. 2011]. Disponible en: http://www.coib.cat/uploadsBO/Noticia/ Documents/SOFROLOGIA\%20AMB\%20ISBN.PDF

2. Comissió de teràpies naturals del COIB. Proposta per a l'obtenció de diplomes d'acreditació (DAC) en 
instruments complementaris de les cures infermeres: Teràpies naturals. Barcelona; 2008. [acceso en: 14 sepn 2011]. Disponible en: http://www.coib.cat/Generiques. aspx? idPagina $=974$ \&idMenu $=-1$

3. López Ruiz J. Integración de las terapias complementarias en el currículo enfermero. Nursing. 2008;26(3):58-63.

4. Saz Peiró P. Situación actual de la medicina naturista. Médicos Descalzos. 2001. [acceso en:14 sep. 2011]. Disponible en: http://www.medicosdescalzos.es/ content/view/773/5/

5. Organización Mundial de la Salud. Estrategia de la OMS sobre medicina tradicional 2002-2005. Ginebra: Organización Mundial de la Salud; 2002

6. NCCAM. What is CAM. [acceso en: 14 sep. 2011]. Disponible en: http://nccam.nih.gov/health/whatiscam

7. Diperri JE. Impacto e integración entre la medicina alternativa y la convencional. Cuad. Fac. Humanid. Cienc. Soc., Univ. Nac. Jujuy 2004;22(5):241-63. [acceso en: 6 de nov 2011]. Disponible en: http://www. scielo.org.ar/scielo.php?script=sci_arttext\&pid=S1668$81042004000100017 \&$ Ing $=$ es\&nrm=iso

8. Instituto Nacional de Estadística (ES) [internet]. Madrid: Ine.es; 2012; [acceso en: 12 feb. 2012]. Disponible en: http://www.ine.es/

9. Snyderman $R$, Weil $A$. Integrative medicine: bringing medicine back to its roots. Arch Intern Med. 2002;162(4):395-7.

10. Katz DL. La integración de la medicina convencional y la no convencional: tendidendo un puente sobre las turbulentas aguas del cuidado de la salud. Humanitas: Humanidades médicas. Medicinas alternativas y complementarias. 2003;1(2):171-80.

11. Zamarra MP. Integración de las terapias naturales en la práctica diaria de Enfermería. Hacia una salud holística. Revista de Especialidades Enfermeras 2006;3(7)[en línea] [acceso en: 14 sep. 2011]. Disponible en: http:// www.especialidadesenfermeras.com/revista/index.htm. 12. Decreto $31 / 2007$ del 30 de Enero (ES). Decreto por el cual se regulan las condiciones para el ejercicio de determinadas terapias naturales. Diari Oficial de la Generalitat de Catalunya; 1 fev. 2007. [acceso en: 7 nov. 2011]. Disponible en: http://www.gencat.cat/ diari/4812/07025003.htm

13. Universidad San Martin de Porres [internet]. Lima: Facultad de Medicina, Universidad San Martin de Porres. V Congreso Mundial de Medicina Tradicional 2005. [acceso en: 14 sep. 2011]. Disponible en: http://www. medicina.usmp.edu.pe/congresomundial/
14. Cooper RA, Stoflet SJ. Trends in the education and practice of alternative medicine clinicians. Health Aff (Millwood). 1996;15(3):226-38.

15. Spiegel D, Stroud P, Fyfe A. Complementary medicine. West J Med. 1998;168(4):241-7.

16. Pelletier KR, Marie A, Krasner M, Haskell WL. Current trends in the integration and reimbursement of complementary and alternative medicine by managed care, insurance carriers, and hospital providers. Am J Health Promot. 1997;12(2):112-22.

17. Ministerio de Educación (ES). [acceso en: 24 de oct 2011]. Disponible en: http://www.guiauniversidades. uji.es/postgrados2010/index.html

18. Teixidor M. La EU. Enfermería Santa Madrona de la Fundación"laCaixa": un proyectoformativoglobal.5Google académico. (Acceso día 10-4-2009) Disponible en:http:// www.fundacio.lacaixa.es/StaticFiles/StaticFiles/ c16934a6c1801110VgnVCM200000128cf10aRCRD/es/ PROYECTOGLOBAL.pdf

19. Fernández Cervilla AB. Salvador Ríos, T. Formación y aplicación de las terapias complementarias en los cuidados de enfermería al paciente oncológico. Nursing. 2010;28(7):52-8.

20. Hernández A, Guardado de la Paz C. La Enfermería como disciplina profesional holística. Rev Cubana Enfermer. 2004;20(2).

21. Sandor MK. Educating the next generation of healers. J Holistic Nurs. 2005;23(2):117-9.

22. Ministerio de Educación, Cultura y Deporte (ES). La integración del sistema universitario español en el espacio europeo de enseñanza superior. Documento Marco. Febrero 2003.

23. Agencia Nacional de Evaluación de la Calidad y Acreditación (ES). Libro Blanco: Título de Grado de Enfermería. Biblioteca Lascasas 2005; p. 1.

24. Almeida $A H$, Soares CB. Health education: analysis of its teaching in undergraduate nursing courses. Rev. Latino-Am. Enfermagem. 2011;19(3):614-21.

25. Guerrero VG, Alvarado OS. Outcome analysis of accreditacion processes for chilean

nursing programs. Rev. Latino-Am. Enfermagem. 2010;18(1):94-101.

26. Nunes ECDA, Silva LWS, Pires EPOR. Nursing professional education: implications of education for transpersonal care. Rev. Latino-Am. Enfermagem. 2011;19(2):252-60. 